\title{
School Bullying: Effecting Childs Mental Health
}

\author{
Tehseen Nazir ${ }^{1}$, Dr. Metin Piskin ${ }^{1}$
}

\section{ABSTRACT}

By the very time parents are trying to protect their children's from the very atrocious situations that their children's were going through. These deteriorating situations involve one of the gruesome acts of bullying. The paper tries to define this act of bullying in relation to the mental health of children's affected with bullying. How their mental, social, physical and cognitive development has been affected. The paper also tries to explore various measures that can help children's to cope up with such difficult problem.

Keywords: Bullying, Mental Health

School bullying is a type of bullying that occurs in an educational setting. Bullying can be physical, sexual, verbal or emotional in nature. Bullying make children's upset, unhappy and may often feel lonely and frightened. It also makes them feel unsafe and they are forced to think that there is something wrong with them. They also lack confidence \& interest of going school and this may end up with their sickness.

School bullying may be more specifically characterized by:

1. An intention to harm: intention suggests that the harm caused by bullying is deliberate, not accidental.

2. Victimization distress: bullying causes the victim to suffer mild to severe psychological, social or physical trauma.

3. Repetition: bullying is persistent; it happens more than once or has the potential to occur multiple times.

4. Power inequity: definitions of bullying often state that bullying includes a real or perceived imbalance of power between the bully and the victim. This characteristic is disputed, as both bullies and victims have reported that the conflict and/or behaviors most commonly occur between two equals.

5. Provocation: bullying is proposed to be a part of progressive aggression: motivated by perceived benefits of their aggressive behaviors.

${ }^{1}$ Dept of Counseling and Guidance, Ankara University, Turkey

(C) 2015 I T Nazir, M Piskin; licensee IJIP. This is an Open Access Research distributed under the terms of the Creative Commons Attribution License (http://creativecommons.org/licenses/by/2.0), which permits unrestricted use, distribution, and reproduction in any Medium, provided the original work is properly cited. 
Bullying comprised of direct behaviors such as teasing, threatening, hitting and stealing .In addition to the direct attacks it's may also indirect by causing a student to be socially isolated through intentional exclusion. While boys typically engage in direct bullying methods, girls who bully are more apt to utilize these more subtle indirect strategies, such as spreading rumors and enforcing social isolation (Ahmad \& Smith, 1994; Smith \& Sharp, 1994). Whether the bullying is direct or indirect, the key component of bullying is that the physical or psychological threats occur repeatedly over time to create an ongoing pattern of harassment and abuse (Batsche \& Knoff, 1994; Olweus, 1993).

\section{TYPES OF BULLYING}

Physical bullying involves hitting, shoving, pushing, tripping, and other kinds of force.

Verbal bullying involves hurtful comments, name-calling, teasing.

Social bullying involves using relationships to hurt someone. It involves excluding or ostracizing someone from a friend group, spreading rumors, or "the silent treatment", it's also known as Covert or Hidden bullying. It may also include mimicking unkindly and playing nasty jokes.

Cyber bullying happens over cell phones or the internet by using digital technologies (computers \& Smartphone's).It may also include ;

- Abusive or hurtful texts, emails or posts, images or videos.

- Nasty gossips or rumors.

- Imitating others, online or using their login.

\section{CHARACTERISTICS OF BULLIES AND VICTIMS;}

- Bullies are those who are engaged in bullying behaviors' seem to have a need to feel powerful \& control.

- They appear to derive satisfaction from inflicting injury and sufferings on others.

- They have little empathy for their victims.

Studies indicate that bullies often come from homes where physical punishment is used, where the children are taught to strike back physically as a way to handle problems, and where parental involvement and warmth are frequently lacking. Students who regularly display bullying behaviors are generally defiant or oppositional toward adults, antisocial, and apt to break school rules. In contrast to prevailing myths, bullies appear to have little anxiety and to possess strong self-esteem. There is little evidence to support the contention that they victimize others because they feel bad about themselves (Batsche \& Knoff, 1994; Olweus, 1993).

- Victims of bullying are generally anxious, insecure, cautious'\& suffer from low selfesteem.

- They can rarely defend themselves when bullied by someone.

- They lack social skills \& friends and are often socially isolated.

- Victims of bullying are very close to their parents. 


\section{School Bullying: Effecting Childs Mental Health}

Major defining physical characteristics of victims of bullying is that they tend to be physically weaker than their peers ,other physical characteristics such as weight, dress, or wearing eyeglasses ,do not appear to be significant factors that can be correlated with victimization .( Batsche \& Knoff , 1994;Olweus,1993)

\section{SIGNS OF BULLING}

Signs of bullying may involve;

- Depression, loneliness, or anxiety

- Low self-esteem

- Headaches, stomachaches, tiredness, or poor eating habits

- Missing school, disliking school, or having poorer school performance than previously

- Self-destructive behaviors, such as running away from home or inflicting harm on oneself

- Thinking about suicide or attempting to commit suicide

- Unexplained injuries

- Lost or destroyed clothing, books, electronics, or jewelry

- Difficulty sleeping or frequent nightmares

\section{MENTAL HEALTH}

'Mental health is defined as a state of well-being in which every individual realizes his or her potential, can cope with the normal stresses of life, can work productively and fruitfully and is able to make a contribution to his or her community' (Promoting Mental Health: Concepts, Emerging Evidence Practice. World Health Organization (WHO, 2005).

Mental health includes our emotional, psychological, and social well-being. It affects how we thi nk, feel, and act. It also helps determine how we handle stress, relate to others, and make choices . Mental health is important at every stage of life, from childhood and adolescence through adult hood. Mental health is an optimal way of thinking, relating to others, and feeling. All of the diag nosable mental disorders fall under the umbrella of mental illness. Depression, anxiety, and subst ance-abuse disorders are common types of mental illness. Symptoms and signs of mental illness i nclude irritability, moodiness, insomnia, headaches, and sadness. Treatment may involve psychot herapy and medication.

\section{SCHOOL BULLYING AND MENTAL HEALTH:}

Bullying can affect everyone- those who are bullied, those who bully, and those who witness bullying. Bullying is linked to many negative outcomes including impacts on mental health, substance use, and suicide. Those who are bullied can experience negative physical, school, and mental health issues. Children's who are bullied are more likely to experience following mental problems; 


\section{School Bullying: Effecting Childs Mental Health}

- Depression and anxiety, increased feelings of sadness and loneliness, changes in sleep and eating patterns, and loss of interest in activities they used to enjoy. These issues may persist into adulthood.

- Health complaints.

- Decreased academic achievement and participation in various schools co curricular activities. They are more likely to miss, skip, or drop out of school because of the prolonged effects of bullying.

Various researchers discovered that children who were bullied are more likely to suffer from anxiety, depression and consider self-harm and suicide later in life. Children can internalize the harmful effects of bullying, which create stress-related issues such as anxiety and depression, or they can externalize it by turning from a victim to a bully themselves. Either way, the result has a painful impact.

Bullying affects young people's mental health, emotional well-being and identity. However, the relationship between bullying and mental health is complicated by the bi-directional nature of these issues: some young people are bullied as a result of their mental health issues; and some young people develop mental health issues as a consequence of being bullied.

The common mental healths problems experienced by children are affected by bullying were;

- Anxiety problems

- Self-harming

- Depression

- Self esteem \& self identity

1. Anxiety and depression; Anxiety problems include social phobias, general anxiety problems, panic attacks \& obsessive compulsive disorder. The victim experience a great fear while participating either in social or school gathering. Victims are scared to talk about bullying and also scared of talking about the effects of bullying on them. Childhood experiences of bullying can also increase the risk of depression in later adolescence and adulthood.

2. Self-harming:-Self -harm is often a reaction to stressor a coping mechanism to deal with anger or emotions that are difficult to deal with. Being bullied in childhood increases the risk of self harming in adolescents. There can be negative attitudes surrounding self harming, which can mistake as attention seeking behavior.

3. Self esteem \& self identity; Prolonged bullying may affects one's self identity, which may have direct effects on ones mental health and it may lead to develop a negative self identity.

"Bullying wears down young children's confidence, their self-esteem, until they're quite depressed, low. And also it leaves them feeling very isolated. Which is why people don't reach out for help with bullying?” 


\section{HOW TO PREVENT BULLYING;}

Bullying is the most contemptible problem among young children's that occurs in every social environment. There is a need to prevent children's from this deteriorating problem that is affecting their mental health as well as their psychological wellbeing. There are a number of ways that can help a young child to cope up with such situation. Not only the children's but the parents, teachers and peers can also help a person to come out of this situation.

Schools need to be aware of young people who may be vulnerable targets of bullying, such as young people with mental health problems, and also be aware of the actions and reactions of other young children's towards those who are vulnerable to bullying. Schools also need to create positive environment for those who have certain mental health difficulties and are vulnerable targets of bullying.

One of the important measures that can help to reduce the occurrence of bullying is communication. Through communication one can easily talk about the conflict that is prevailing within them.

Schools need to ensure that young children's feel able to talk about bullying and how it affects their emotional wellbeing. Knowledge about bullying and its impact on mental health should be taught throughout the school curriculum, in order to develop general awareness about the challenges young children's experience. And also to develop strategies for supporting children's, who are going through mental health issues \& also emotional instability. It is also important to create awareness among school administration about the impact of gruesome act of bullying, so that nobody can get involved in such a heinous act.

Teachers can work with students at the class level to develop class rules against bullying. Many programs engage students in a series of formal role-playing exercises and related assignments that can teach those students directly involved in bullying alternative methods of interaction. These programs can also show other students how they can assist victims and how everyone can work together to create a school climate where bullying is not tolerated (Sjostrom \& Stein, 1996).

\section{CONCLUSION}

Bulling is a very serious problem that can dramatically affect children's ability to progress socially and academically. Thus for this serious issue parents, teachers and administration need to address the reasons why a person get involved in such a woeful act and what measures can be taken in order to stop this act . 


\section{REFERENCES}

About.com (2006, July 25). What is Mental Health?. Retrieved June 1, 2007, from About.com

Johns Hopkins University.(2077).Origins of Mental Health. Retrieved June 14, 2010, from JHSP H.edu

Ron Banks.Bullying in schools- Educational Resource Information Centre(U.S.Dept of Education) June15,2013

www.livescience.com/43431-bullying-effects-children-mental-health-html

www.pathstonementalhealth.ca/bullying/effects-bullying 